\title{
Interest of SAAG in Etiological Diagnosis of Ascites in African Black
}

\author{
Okon Anassi Jean Baptiste ${ }^{1}$, Soro Dramane ${ }^{2}$, Doffou Stanislass ${ }^{2}$, Diakite Mamadou ${ }^{1}$, \\ Koné Amadou', Aké Fabrice', Thot'o Amani Sroboua1, N'dri N'guessan'1
}

\author{
${ }^{1}$ Hepato-Gastroenterology Department, University Hospital Center, Bouaké, Ivory Coast \\ ${ }^{2}$ Hepato-Gastroenterology Department, University Hospital Center, Abidjan, Ivory Coast \\ Email: okonanassi@yahoo.fr
}

How to cite this paper: Baptiste, O.A.J., Dramane, S., Stanislass, D., Mamadou, D., Amadou, K., Fabrice, A., Sroboua, T.A. and N'guessan, N. (2018) Interest of SAAG in Etiological Diagnosis of Ascites in African Black. Open Journal of Gastroenterology, 8, 337-347.

https://doi.org/10.4236/ojgas.2018.810036

Received: August 5, 2018

Accepted: October 13, 2018

Published: October 16, 2018

Copyright $\odot 2018$ by authors and Scientific Research Publishing Inc. This work is licensed under the Creative Commons Attribution International License (CC BY 4.0).

http://creativecommons.org/licenses/by/4.0/

\begin{abstract}
Purpose: To show the interest of the serum-ascites concentration gradient in albumin (SAAG) in the etiological diagnosis of ascites in African black. Materiel and Methods: This was a monocentric observational and analytical study performed on patients over 15 years old and hospitalized in the Hepato-Gastroenterology department of Cocody from January 1st, 2010 to March 31st, 2017 for ascites. The cytology and chemistry of the ascites fluid and the protidogram were performed. The main outcome measure was the prediction of portal hypertension (PHT) or non-portal hypertension related causes of ascites from SAAG. Results: The hospital prevalence of ascites was $11 \%$. There were 82 women $(46.9 \%)$ and 93 men $(53.1 \%)$ with a sex ratio $(\mathrm{M} / \mathrm{F})$ of 1.1 . SAAG was low in $68.6 \%$ of cases and high in $31.4 \%$ of cases. The most common etiologies were post-viral cirrhosis (74\%), HCC (16.60\%) and peritoneal tuberculosis (13.7\%) respectively. In the case of high SAAG, $91 \%$ of ascites related to PHT were observed, but also $77.5 \%$ of a low SAAG corresponded to ascites related to PHT ( $\mathrm{p}=0.024)$ with $\mathrm{Se}=35 \% \mathrm{Sp}=84 \%$ and accuracy $=44 \%$. All patients with peritoneal tuberculosis had a SAAG low of less than $1.1 \mathrm{~g} / \mathrm{dl}$ significantly $(\mathrm{p}=0.002)$. SAAG had a diagnostic performance of $89 \%$ in peritoneal tuberculosis at the cutoff value of -1.24 $\mathrm{g} / \mathrm{dl}($ AUROC $=0.91, \mathrm{Se}=96 \%, \mathrm{Sp}=86 \%$ ) while in post viral hepatitis cirrhosis at a threshold of $0.58 \mathrm{~g} / \mathrm{dl}$ the diagnostic performance was $60 \%$ (AUROC $=0.69, \mathrm{Se}=53 \%, \mathrm{Sp}=79 \%$ ). Conclusion: The simple technical SAAG, allowing to distinguish the ascites linked to the PHT and the ascites not bound to the PHT, can be used like a method of diagnosis of the etiologies of the ascites especially in the peritoneal tuberculosis in the African countries low income.
\end{abstract}

\section{Keywords}

SAAG, Ascites, Peritoneal Tuberculosis, Cirrhosis, PHT 


\section{Introduction}

The causes of ascites are multiple, nevertheless two etiologies predominate, liver cirrhosis for transudative ascites and peritoneal tuberculosis for exudative ascites in our contexts. Traditionally, ascites is classified according to the concentration of proteins in ascites fluid in transudate (Proteins $<30 \mathrm{~g} / \mathrm{l}$ ) and exudate (Proteins $\geq 30 \mathrm{~g} / \mathrm{l}$ ) [1]. However, several authors have demonstrated the superiority of serum albumin ascites concentration (SAAG) in distinguishing causes of ascites related to portal hypertension when it is $\geq 1.1 \mathrm{~g} / \mathrm{dl}$ and causes of ascites unrelated to portable hypertension for SAAG $<1.1 \mathrm{~g} / \mathrm{dl}$ [2] [3]. In Africa in general and in sub-Saharan Africa in particular, much work has been done on ascites, but few studies have indicated the interest of SAAG in the etiological diagnosis of ascites [4] [5] [6] [7]. It is therefore questionable whether SAAG has the same diagnostic value in the etiological research of ascites in Africans as in Caucasians. Our study therefore aimed to clarify the interest of the ascites serum albumin gradient (SAAG) in the etiological diagnosis of ascites by assessing its threshold value in the diagnosis of cirrhosis and peritoneal tuberculosis in Black Africans.

\section{Materials and Methods}

It was an observational, analytical, and monocentric study that took place in the Hepato-gastroenterology department of the University Hospital Center (CHU) in Cocody, Abidjan (Côte d'Ivoire). The population studied consisted of black African patients hospitalized in the Hepato-gastroenterology department, during the period from January 2010 to March 2017 for ascites. Ascites was confirmed on abdominal and pelvic ultrasonography and/or CT and objectified by ascites puncture. The cytology and chemistry of the ascites fluid and the protidogram were performed. Data were collected from the complete medical records of patients hospitalized for ascites in the hepato-gastroenterology department during the study period and collected from a survey sheet.

\subsection{The Inclusion Criteria}

Included in the study were patients with:

- presented clinical ascites, diagnosed on the abdomino-pelvic ultrasound and objectified by the puncture.

- performed the cyto-chemical analysis of the ascites fluid.

- made a protidogram.

\subsection{Were Not Included in the Study}

- Patients with incomplete blood test and ascitic fluid status.

- Patients seen on an outpatient basis during this study period.

- Caucasian and non-African patients.

The main outcome measure was the prediction of portal hypertension (PHT) or non portal hypertension (non-PHT) related causes of ascites from SAAG, 
which is as follows:

$\mathrm{SAAG}=[$ Serum albumin concentration $]-[$ Concentration of ascites fluid albumin].

Albuminemia is obtained by the protidogram. Its normal value is between 30 and $40 \mathrm{~g} / \mathrm{l}[8]$.

Albumin (Protein levels) in the ascites fluid is obtained by biochemical examination of the ascites fluid. Thus we defined a transudate if the protein level is less than $25 \mathrm{~g} / \mathrm{l}$ and an exudate if the protein level exceeds $25 \mathrm{~g} / \mathrm{l}$ [9]. The determination of the albumin concentration in the blood and in the ascites fluid was made using the bromcresol blue method (Biolabo ${ }^{\circledR}$ Reagents, Maizy, France) by the Hitachi ${ }^{\otimes} 704$ Automatic Analyzer (Borhinger Mannheim Germany). The blood and ascites fluid samples for SAAG were done in less than 24 hours. The criteria of secondary judgments made it possible, on the one hand, to determine the correlation between the level of SAAG and the etiologies of ascites; so we defined three levels of SAAG:

- $\quad$ SAAG $<1.1 \mathrm{~g} / \mathrm{dl}$;

- SAAG [1.1 - 1.49] g/dl;

- $\mathrm{SAAG}>1.5 \mathrm{~g} / \mathrm{dl}$.

SAAG high, that is to say greater than or equal to $1.1 \mathrm{~g} / \mathrm{dl}$ corresponding to ascites related to PHT and low SAAG, less than $1.1 \mathrm{~g} / \mathrm{dl}$ corresponding to unbound ascites at the PHT. On the other hand, these criteria made it possible to classify the etiologies of ascites into two groups. Ascites related to PHT (posthepatic hepatic cirrhosis, alcoholic cirrhosis, hepatosplenic schistosomiasis, hepatocellular carcinoma (HCC), heart disease) and non-PHT ascites (peritoneal tuberculosis, peritoneal carcinomatosis, ovarian tumor, nephropathy). The diagnosis of these etiological lesions was based on the clinical, biological and morphological elements.

The data were captured using the EPI info software and the statistical analysis was done by SPSS 20. The results were expressed as a percentage (\%) for the qualitative variables and as an average \pm standard deviation for the values quantitative. The chi-square test was used for qualitative variables and the Student's test for quantitative variables. The analysis of the area under the ROC curve (AUC) enabled us to determine the specificity (Sp), the sensitivity (Se) and the diagnostic efficiency (ED) of GASA in the etiological diagnosis of ascites. The significance level of the tests was fixed at $5 \%$.

\section{Results}

Of the 10,282 patients hospitalized during the study period, 1088 were admitted for ascites over the study period 175 patients were selected according to the inclusion criteria. The hospital prevalence of ascites was $11 \%$. There were 82 women $(46.9 \%)$ and 93 men $(53.1 \%)$ with a sex ratio $(\mathrm{M} / \mathrm{F})$ of 1.1 . The average age was 46 years old with extremes of 16 years and 90 years. Patients consulted for abdominal distension in $86 \%$ of cases. 
The median of biology summarized in Table 1.

The ascites fluid was citrine in $70.3 \%$ of cases. Cellularity was significant in $43.9 \%$ of cases. The ascites fluid was transudative in $69 \%$ of cases and exudate in $31 \%$ of cases. Albuminemia was less than $28 \mathrm{~g} / \mathrm{l}$ in $66.3 \%$ of cases with an average albumin of $24 \mathrm{~g} / \mathrm{l}$. SAAG was low in $68.6 \%$ of cases and high in $31.4 \%$ of cases.

The etiologies of ascites are summarized in Table 2.

The most common etiologies were post-viral cirrhosis (74\%), HCC (16.60\%) and peritoneal tuberculosis (13.7\%) respectively.

\section{Correlation between Levels of SAAG and Etiologies of Ascites}

In the case of high SAAG, $91 \%$ of ascites related to PHT were observed, but also $77.5 \%$ of a low SAAG corresponded to ascites related to PHT ( $\mathrm{p}=0.024$ ) with Se $=35 \% \mathrm{Sp}=84 \%$ and accuracy $=44 \%$. All patients with peritoneal tuberculosis had a SAAG low of less than $1.1 \mathrm{~g} / \mathrm{dl}$ significantly $(\mathrm{p}=0.002)$. Post-hepatitis cirrhosis was found in patients with transudative ascites fluid (Protein $<25 \mathrm{~g} / \mathrm{l}$ ) in $71.30 \%$ of cases, with a statistically significant relationship $(\mathrm{p}<0.05)$ with $\mathrm{Se}=$ $71,32 \% \mathrm{Sp}=57.58 \%$ and accuracy $=74.2 \%$ (Table 3 ).

Table 1. Distribution of patients according to the median of the laboratory test in the etiologies of ascites.

\begin{tabular}{cccccccccccc}
\hline & $\begin{array}{c}\text { all } \\
\text { patients }\end{array}$ & CV & COH & BILH & CP & HCC & NP & CP & TBC p & Tm ov \\
\hline $\begin{array}{c}\text { Lymphocytes } \\
\text { ascites }\end{array}$ & 448 & 361.00 & 62.50 & 798.50 & 844.5 & 292.00 & 326.00 & 598.0 & 1681.58 & 177.00 \\
$\begin{array}{c}\text { Lymphocytes } \\
\text { blood }\end{array}$ & 1616 & 1715.00 & 925.50 & 1484.00 & 1189.00 & 1608.00 & 2077.00 & 1470.0 & 1426 & 1485.00 \\
PNN blood & 3267.50 & 3235.00 & 3584.00 & 2380.00 & 4708.50 & 4030.00 & 3150.00 & 3312.00 & 4372.50 & 1650.00 \\
Albuminemia & 24.4 & 24.15 & 23.52 & 28.07 & 26.9 & 24.60 & 24.90 & 29.45 & 25.15 & 35.50 \\
Total proteins & 68 & 69.00 & 65.05 & 61.05 & 73 & 72.00 & 62.00 & 66.50 & 68.50 & 68.00 \\
SAAG & 0.46 & 0.73 & -0.05 & 1.61 & -1.875 & 0.50 & -0.27 & 0.64 & -2.965 & -0.55 \\
Cellularity & 530 & 456 & 72.00 & 875.00 & 1076.50 & 400.00 & 314 & 762.50 & 1222.00 & 253.00 \\
\hline
\end{tabular}

CV: viral cirrhosis, COH: alcoholic cirrhosis, CP: peritoneal carcinoma, HCC: hepatocellular carcinoma, NP: nephropathy, CP: cardiopathy, TBC p: peritoneal tuberculosis, Tm ov: ovarian tumor, BILH: Hepatic bilharzia.

Table 2. Distribution of patients according to the etiology of ascites.

\begin{tabular}{ccc}
\hline Etiology & $\mathbf{n}$ & \% \\
\hline Cirrhosis & 135 & 77.4 \\
Hepatocellular carcinoma & 29 & 16.6 \\
Peritoneal tuberculosis & 24 & 13.7 \\
Nephropathy & 11 & 6.3 \\
Peritoneal carcinoma & 6 & 3.4 \\
Cardiopathy & 6 & 3.4 \\
Hepatic bilharzia & 4 & 2.3 \\
Ovarian tumor & 3 & 1.7 \\
\hline
\end{tabular}


Table 3. Distribution of patients according to levels of SAAG and etiologies of ascites.

\begin{tabular}{|c|c|c|c|c|c|c|c|c|}
\hline \multirow{2}{*}{ Levels of SAAG } & \multicolumn{2}{|c|}{$<1.1$} & \multicolumn{2}{|c|}{$[1.1-1.49]$} & \multicolumn{2}{|c|}{$>1.50$} & \multirow{2}{*}{ Total } & \multirow{2}{*}{$\mathrm{p}$} \\
\hline & $\mathbf{n}$ & $\%$ & $\mathbf{n}$ & $\%$ & $\mathbf{n}$ & $\%$ & & \\
\hline Viral cirrhosis & 81 & $62.8 \%$ & 14 & $10.9 \%$ & 34 & $26.4 \%$ & 129 & 0.019 \\
\hline Alcoholic cirrhosis & 5 & $83.3 \%$ & 0 & 0 & 1 & $16.7 \%$ & 6 & 0.646 \\
\hline Hepatic bilharzia & 2 & $50.0 \%$ & 0 & 0 & 2 & $50.0 \%$ & 4 & 0.348 \\
\hline HCC & 21 & $72.4 \%$ & 4 & $13.8 \%$ & 4 & $13.8 \%$ & 29 & 0.433 \\
\hline $\mathrm{CP}$ & 5 & $83.3 \%$ & 0 & 0 & 1 & $16.7 \%$ & 6 & 0.646 \\
\hline $\begin{array}{l}\text { Peritoneal } \\
\text { tuberculosis }\end{array}$ & 24 & $100.0 \%$ & 0 & 0 & 0 & $0 \%$ & 24 & 0.002 \\
\hline Nephropathy & 8 & $72.7 \%$ & 1 & $9.1 \%$ & 2 & $18.2 \%$ & 11 & 0.950 \\
\hline Cardiopathy & 4 & $66.7 \%$ & 0 & 0 & 2 & $33.3 \%$ & 6 & 0.609 \\
\hline Ovarian tumor & 3 & $100 \%$ & 0 & 0 & 0 & $0 \%$ & 3 & 0.497 \\
\hline
\end{tabular}

HCC: hepatocellular carcinoma, CP: peritoneal carcinoma.

The diagnostic performance of SAAG, ascites fluid proteins and lymphocytosis in the main etiologies are compared through the ROC curves of Figures 1-6.

1) Diagnostic performance of SAAG in post-hepatitis cirrhosis.

2) Diagnostic performance of GASA in peritoneal tuberculosis.

3) Diagnostic performance of ascites fluid proteins in peritoneal tuberculosis.

4) Diagnostic performance of ascites fluid proteins in cirrhosis.

5) Diagnostic performance of lymphocytes in ascitic fluid in peritoneal tuberculosis.

6) Diagnostic performance of ascitic fluid lymphocytes in post-hepatitic cirrhosis.

\section{Discussion}

Ascites accounted for $10.8 \%$ of ailments during our study period, and male dominance was superimposed on African data [7] [10]. The transudative character and average cellularity of less than 250 elements $/ \mathrm{mm}^{3}$ were consistent with previous studies on the continent [7] [10] [11]. Most of our patients had albuminemia $<28 \mathrm{~g} / \mathrm{l}$ or $66.3 \%$ of cases with an average albumin of $24 \mathrm{~g} / \mathrm{l}$. These results were also found in the study by Gnonko [11] and Sidibé [10]. On the other hand, they were far inferior to those of European literature where albuminemia varies between $30-37 \mathrm{~g} / 1$ [12] [13]. Okon [14] pointed out in a similar study that severe malnutrition in cirrhotic patients was responsible for hypoalbuminemia. Our study indicated that the most common causes of ascites were viral post-hepatitis cirrhosis (74\%), HCC (16.6\%) and peritoneal tuberculosis (13.7\%) in accordance with data from African studies [7] [10] [11]. In Europe, etiologies were dominated by alcoholic cirrhosis and HCC [15] [16]. The low gradient (SAAG $<1.1 \mathrm{~g} / \mathrm{dl}$ ) predominated in our study as in that of Gnonko [11]. These results were contrary to those of European and Asian studies [15] [16] in which upper SAAG predominated. According to Okon and 


\section{Curve ROC / SAAG_Cirrhosis / AUC $=0.693$}

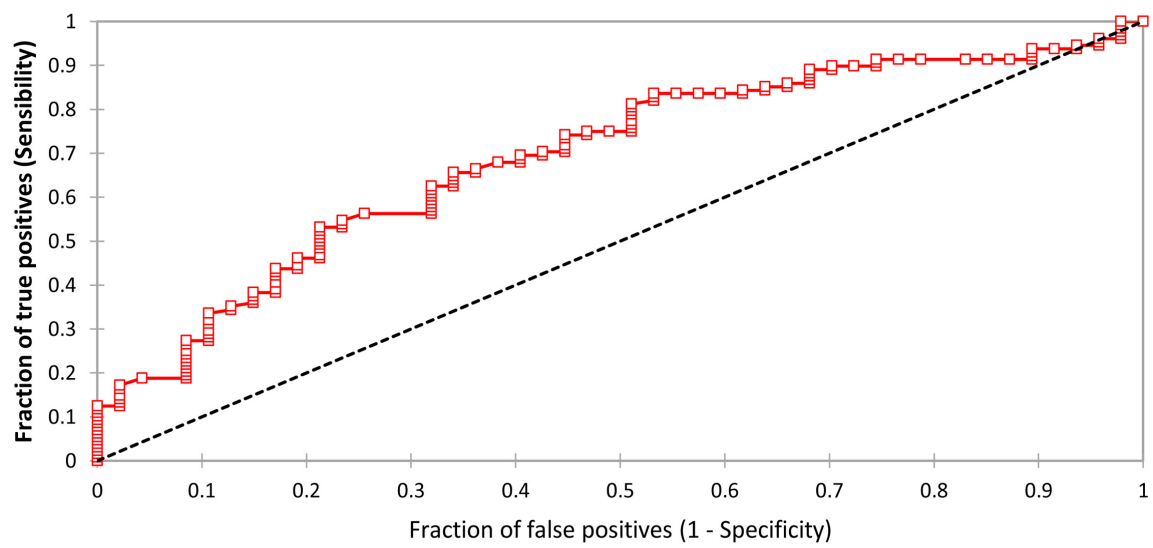

Figure 1. ROC curve of SAAG diagnostic performance in posthepatitis cirrhosis. The area under the ROC curve (AUC) is 0.69 . Cut-off $=0.58, \mathrm{Se}=53 \%, \mathrm{Sp}=79 \%, \mathrm{VPP}=$ $87 \%, \mathrm{VPN}=38 \%, \mathrm{VP}=68, \mathrm{VN}=37, \mathrm{FP}=10, \mathrm{FN}=60$, diagnostic accuracy $=60 \% . \mathrm{p}<$ 0.0001 .

\section{Curve ROC / SAAG_Tuberculosis/ AUC $=\mathbf{0 . 9 1 2}$}

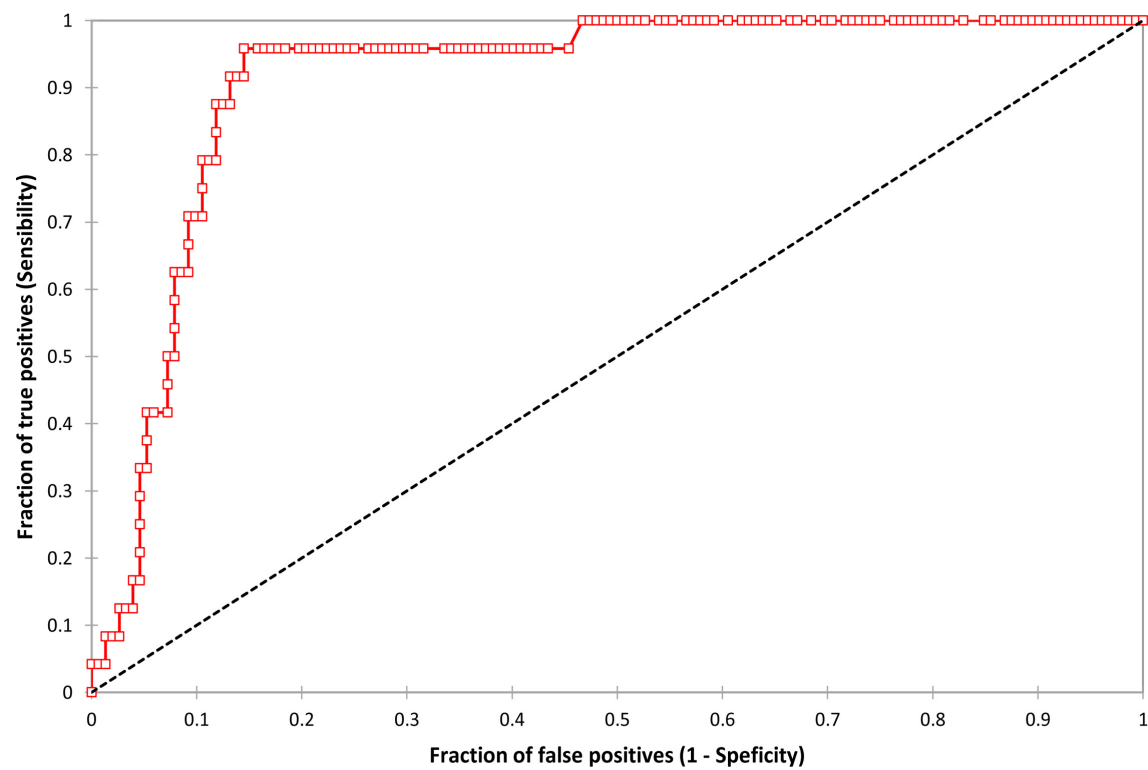

Figure 2. ROC curve of the diagnostic performance of SAAG in peritoneal tuberculosis. The area under the ROC curve (AUC) is 0.911 . For the cut-off value of $-1.24 \mathrm{~g} / \mathrm{dl}$, the sensitivity and specificity are respectively $96 \%$ and $86 \%$ with a diagnostic efficiency of $89 \%$. VPP $=51 \%, \mathrm{VPN}=99 \%, \mathrm{VP}=23, \mathrm{VN}=130, \mathrm{FP}=22, \mathrm{FN}=1 . \mathrm{p}<0.0001$.

Gnonko [11] [14], this prevalence of low SAAG is explained by the state of undernutrition of the patients and the infection of the ascites fluid. Thus, undernutrition leads to hypoalbuminemia, which decreases the value of SAAG while infection of the ascites fluid increases the level of protein, which also lowers the SAAG level in these patients [11] [14]. Several studies [17] [18] have shown the superiority of SAAG in distinguishing ascites with or without PHT with a threshold value of $1.1 \mathrm{~g} / \mathrm{dl}$. In a Chinese study [19], the authors reported 
Curve ROC / Ascites Proteins_Tuberculosis / AUC=0.921

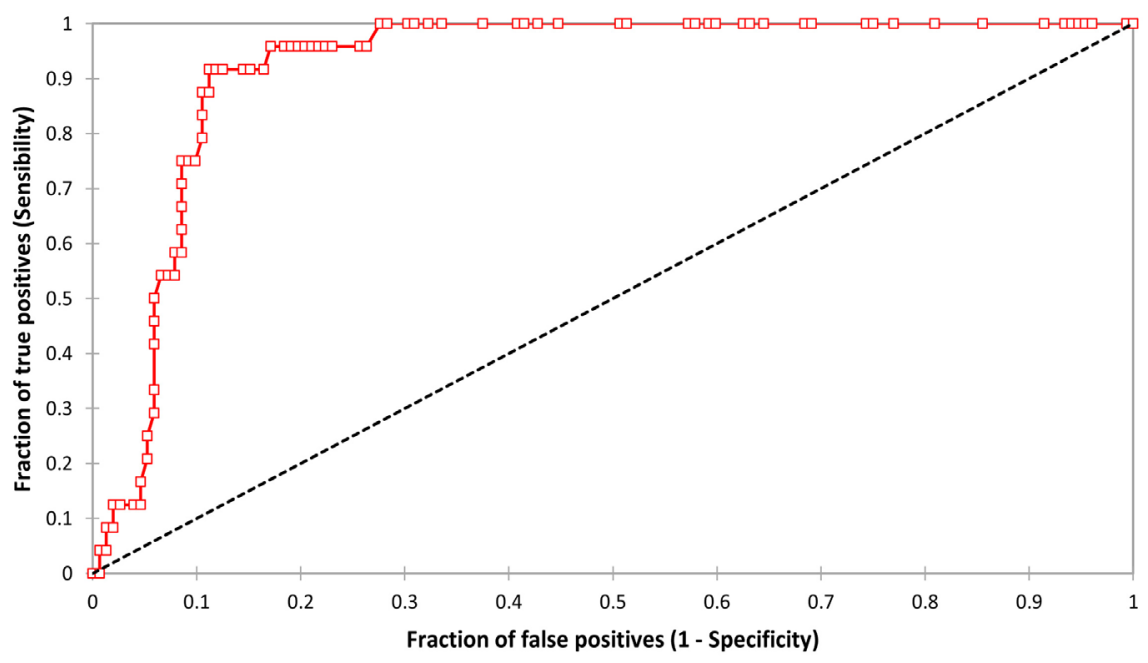

Figure 3. ROC curve of the diagnostic performance of ascites proteins in peritoneal tuberculosis. The area under the ROC curve (AUC) is 0.92 . For the cut-off value of $43 \mathrm{~g} / \mathrm{l}$, sensitivity and specificity are $92 \%$ and $89 \%$, respectively, with a diagnostic efficiency of $89 \%$. VPP $=56 \%, \mathrm{VPN}=98 \%, \mathrm{VP}=22, \mathrm{VN}=135, \mathrm{FP}=17, \mathrm{FN}=2 . \mathrm{p}<0.0001$.

\section{Curve ROC / Ascites-Proteins_cirrhosis/ AUC $=\mathbf{0 . 7 0 5}$}

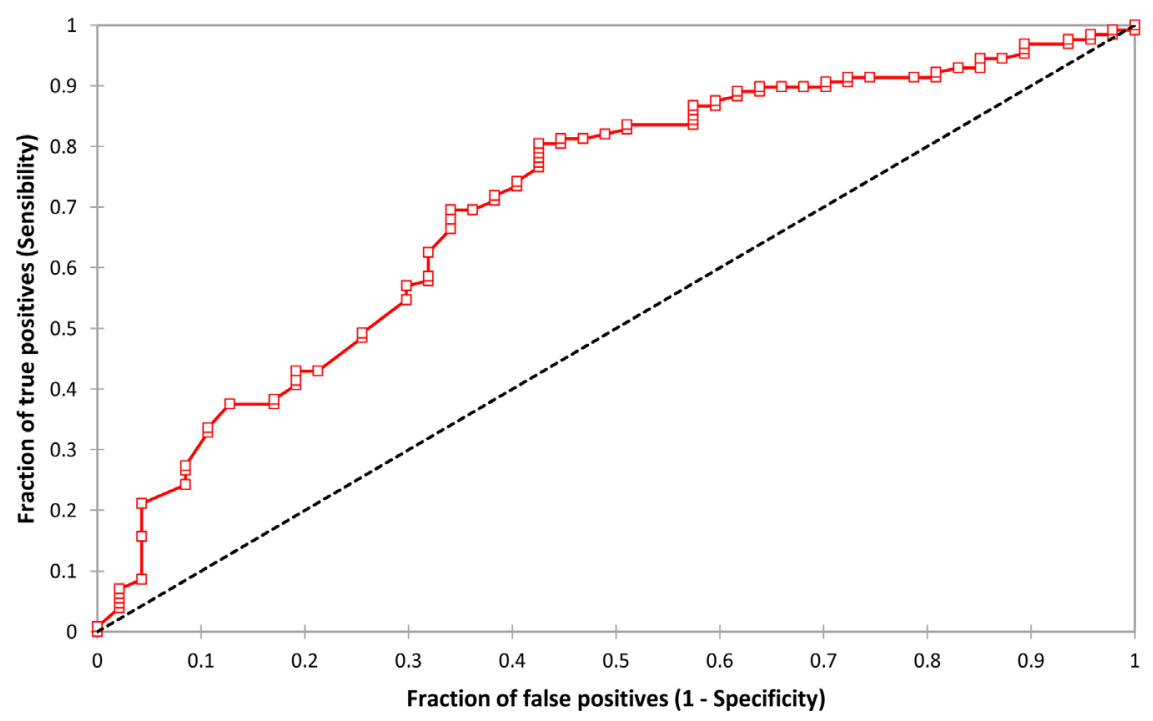

Figure 4. ROC curve of diagnostic performance of ascites fluid proteins in cirrhosis. AUROC $=0.70$, Seuil $=32, \mathrm{Se}=81 \%, \mathrm{Sp}=57 \%, \mathrm{VPP}=84 \%, \mathrm{VPN}=52 \%, \mathrm{VP}=103, \mathrm{VN}=$ $27, \mathrm{FP}=20, \mathrm{FN}=25$, diagnostic accuracy $=74.3 \%$. $\mathrm{p}<0.0001$.

that by using the higher threshold value of SAAG at $1.25 \mathrm{~g} / \mathrm{dl}$, knowledge of the mechanism of occurrence of ascites was better with a sensitivity and specificity respectively of $99.2 \%$ and $95.10 \%$ and a diagnostic accuracy estimated at $97.65 \%$. Our results showed a significant link $(\mathrm{p}<0.05)$ between SAAG and the mechanism of ascites occurring similar to those in the literature [15] [17] [19]. But with SAAG and ascites related to PHT, our data was different. At a cut-off of $1.5 \mathrm{~g} / \mathrm{dl}$ of SAAG, ascites was related to PHT but with a relatively low diagnostic 
Curve ROC / Ascites lymphocytes_Tuberculosis / AUC $=0.706$

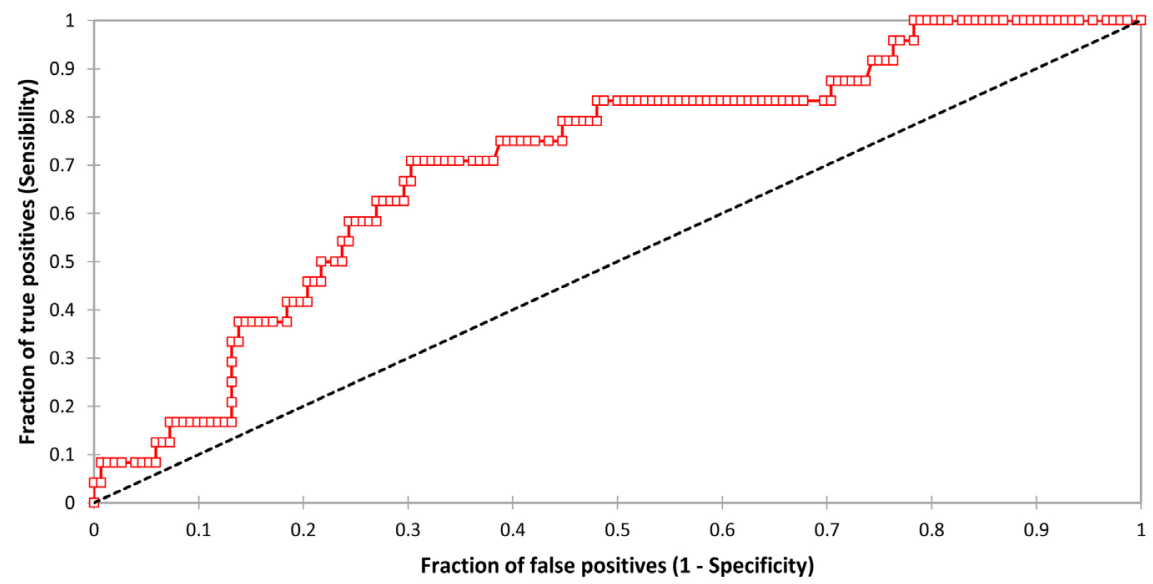

Figure 5. ROC curve of the diagnostic performance of ascitic fluid lymphocytes in peritoneal tuberculosis. The area under the ROC curve (AUC) is 0.706 . For the cut-off value of 770 elts $/ \mathrm{mm}^{3}$, sensitivity and specificity are respectively $71 \%$ and $70 \%$ with a diagnostic efficiency of $70 \%$. $\mathrm{VPP}=27 \%, \mathrm{VPN}=94 \%, \mathrm{VP}=17, \mathrm{VN}=106, \mathrm{FP}=46, \mathrm{FN}=$ 7. $\mathrm{p}=0.00001$.

Curve ROC / Ascites lymphocytes_cirrhosis / AUC $=\mathbf{0 . 5 7 3}$

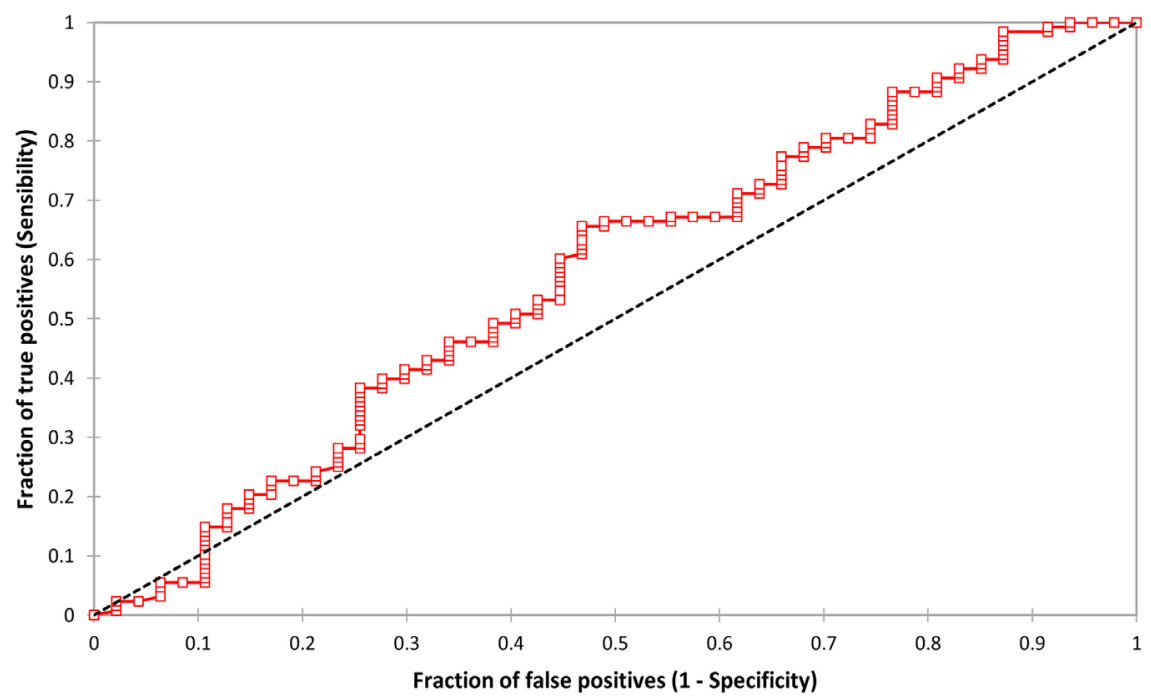

Figure 6. ROC curve of the diagnostic performance of ascitic fluid lymphocytes in post-hepatitic cirrhosis. AUROC $=0.57$. Cut-off $=672, \mathrm{Se}=66 \%, \mathrm{Sp}=53 \%, \mathrm{VPP}=79 \%$, $\mathrm{VPN}=36 \%, \mathrm{VP}=84, \mathrm{VN}=25, \mathrm{FP}=22, \mathrm{FN}=44$, diagnostic accuracy $=62 \% . \mathrm{p}=1.46$.

performance (44\%). More than half of the patients in our study with low SAAG had PHT-related ascites. Torres et al. reported that $56 \%$ of alcoholic cirrhotic patients, $16 \%$ of those with HCC, $12 \%$ of those with non-alcoholic cirrhosis had ascites due to PHT and related to high SAAG. They also indicated, in the same study, that in cases of low SAAG, etiologies were represented by peritoneal tuberculosis in $50 \%$ of cases and peritoneal carcinomatosis in $33.3 \%$ of cases [16]. Other authors, however, noted that all cirrhotic patients had SAAG $\geq 1.1$ g/dl [15] [17] [19] [20]. In our study, causes of ascites significantly related to 
SAAG were cirrhosis of viral origin and peritoneal tuberculosis. However, our results demonstrated a low rate of cirrhotic patients in relation to SAAG $\geq 1.1$ g/dl (only $37.2 \%$ of cirrhosis had a SAAG high) contrary to the articles evoked. Regarding peritoneal tuberculosis, our results were consistent with those of the literature that is to say all patients (100\%) had a low SAAG $<1.1 \mathrm{~g} / \mathrm{dl}$ [13] [15] [17] [19]. In our study, there was a positive correlation between post-hepatitic cirrhosis and a transudative ascites fluid, between peritoneal tuberculosis, ovarian tumor, and the exudative fluidity of ascites fluid according to literature data [17] [20]. Regarding the diagnosis of post-hepatitis cirrhosis by SAAG, the area under the ROC curve (AUC) was 0.69 . With the SAAG cut-off value of 1.1 $\mathrm{g} / \mathrm{dl}$, the sensitivity and specificity were respectively $37 \%$ and $87 \%$ with a diagnostic efficiency of $50.3 \%$. At a rate of SAAG $\geq 1.5 \mathrm{~g} / \mathrm{dl}$ sensitivity increased to $27 \%$ and an improvement in the specificity was observed at $91 \%$, but the diagnostic performance was very low estimated at $44 \%$. By against the cut-off value of $0.58 \mathrm{~g} / \mathrm{dl}$, the sensitivity and specificity were better $53 \%$ and $79 \%$ respectively. At this cut-off, the SAAG confirmed the diagnosis of cirrhosis in $60 \%$ of cases. These results were contrary to those in the literature which indicated that cirrhosis was diagnosed at SAAG $\geq 1.1 \mathrm{~g} / \mathrm{dl}$ with sensitivity and specificity greater than 90\% [17] [18] [19]. The SAAG as a diagnostic tool for peritoneal tuberculosis, the area under the ROC curve (AUROC) was 0.91 testifying to a fairly good diagnostic performance of SAAG in etiological research of ascites of peritoneal tuberculosis. For the threshold value of $1.1 \mathrm{~g} / \mathrm{dl}$, the SAAG predicted peritoneal tuberculosis with a sensitivity of $100 \%$ but a low diagnostic specificity and efficiency respectively $36 \%$ and $45 \%$. More than half of the patients could not be diagnosed by considering this threshold. For a cut-off value of -1.24 $\mathrm{g} / \mathrm{dl}$, the diagnostic performance of SAAG was better at $89 \%$ (Se $=96 \%, \mathrm{Sp}=$ $86 \%$ ). Mahassadi et al. In a similar study conducted at the Yopougon University Hospital Center in 2008, had a diagnostic efficiency of $60 \%$ for a threshold of $0.87 \mathrm{~g} / \mathrm{dl}$ of SAAG ( $\mathrm{Se}=96 \%, \mathrm{Sp}=42 \%$ ) [13]. Considering a lower threshold, there was better diagnostic performance of SAAG in the diagnosis of peritoneal tuberculosis due to the factors of undernutrition and ascites fluid infection. In this study, SAAG performed less well than proteins in the diagnosis of cirrhosis, but the diagnostic performance of SAAG and ascites proteins for the diagnosis of tuberculosis was similar and fairly good in view of the respective ROC curves with values respective thresholds of $43 \mathrm{~g} / \mathrm{l}$ and -1.24 . In our study, lymphocytosis alone was not a good diagnostic test for peritoneal tuberculosis as shown by the area under the ROC curve. These two parameters were far superior to lymphocytosis for the diagnosis of tuberculosis. These results were also reported by Mahassadi, who recommended combined tests (SAAG + liquid ascites + lymphocytosis) for the diagnosis of tuberculosis in the absence of confirmatory histological examination [13]. In this study SAAG was an excellent marker for the etiological diagnosis of ascites compared to ascites protein concentration as proved by some authors [17] [18] [19] [20]. 


\section{Conclusion}

The SAAG contribution to the diagnosis of peritoneal tuberculosis was excellent (AUROC $=0.91, \mathrm{Se}=96 \%, \mathrm{Sp}=86 \%$ ) comparable to that of proteins in the ascites fluid (AUROC $=0.92, \mathrm{Se}=92 \%, \mathrm{Sp}=89 \%$ ) and greater than that of lymphocytosis (AUROC $=0.70, \mathrm{Se}=71 \%, \mathrm{Sp}=70 \%$ ). In contrast, the diagnostic performance of SAAG in the diagnosis of cirrhosis was relatively moderate (AUROC $=0.69)$ and lower than that of literature data due to malnutrition and ascites fluid infection. In black African subjects, threshold values of SAAG considered effective for the etiological diagnosis of ascites were significantly lower due to nutritional and infectious factors. Despite these confounding factors, the SAAG had a good diagnostic performance especially in peritoneal tuberculosis at a threshold of $-1.24 \mathrm{~g} / \mathrm{dl}$ (AUROC $=0.91$, $\mathrm{Se}=96 \%, \mathrm{Sp}=86 \%$ ). Thus, in low-income sub-Saharan African countries where investigative methods are insufficient, SAAG, a simple technique, can be used as a method of diagnosing etiologies of ascites, especially in peritoneal tuberculosis. Further prospective multicenter studies should be conducted to validate the diagnostic accuracy of this minimally invasive test in the etiological diagnosis of ascites in underdeveloped countries by correcting for confounding factors.

\section{Conflicts of Interest}

The authors declare no conflicts of interest regarding the publication of this paper.

\section{References}

[1] Ozalp, S., Yalcin, O.T., Tanir, H.M. and Kabukcuoglu, A. (2001) Pelvic Tuberculosis Mimicking Signs of Abdominopelvic Malignancy. Gynecologic and Obstetric Investigation, 52, 71-72. https://doi.org/10.1159/000052945

[2] Hoefs, J.C. (1983) Serum Protein Concentration and Portal Pressure Determine the Ascites Fluid Protein Concentration in Patients with Chronic Liver Disease. Journal of Laboratory and Clinical Medicine, 102, 260-273.

[3] Runyon, B.A., Montano, A.A. and Akriviadis, E.A. (1992) The Serum-Ascites Albumin Gradient in the Differential Diagnosis of Ascites Is Superior to the Exudate-Transudate Concept. Annals of Internal Medicine, 117, 215-220. https://doi.org/10.7326/0003-4819-117-3-215

[4] Amon, K.G. (2010) Epidemiological, Clinical, Biological, Aetiological, Therapeutic, and Evolving Profile of Hospital Ascites. Thesis Medicine, Abidjan.

[5] Dembélé, M., Maiga, M.Y., Minta, D.K., Traoré, A.S., Sacko, M. and Traoré, A.K. (2003) Peritoneal Tuberculosis in a Medicine Department in the Tropics: Clinical, Biological and Laparoscopic, Bamako-Mali. Acta Endoscopica, 33, 561-567.

[6] Diarra, A.B. (2009) Infection of Ascites Fluid in Cirrhotic Patients in the Hepatogastroenterology Department of the Gabriel Touré Teaching Hospital. Thesis Medicine, Bamako, 1123.

[7] Kouadiani, A.M. (2010) Epidemiological, Clinical, Paraclinical, Etiological and Evolutionary Aspects of Ascites in the Department of Internal Medicine of the University Hospital of Treichville. Thesis Medicine, Bouaké, 77. 
[8] Rossary, A., Blondé-Cynober, F. and Bastard, J.-P. (2017) Albuminémie: Les enjeux analytiques dans le cadre de l'évaluation nutritionnelle. Etude Comparative Multicentrique Française, 75, 305-318.

[9] Naveau, S., Balian, A. and Perlemuter, G. (2003) Ascite. Hépatogastroenterol, 3, $32-41$.

[10] Dembélé, Y. (2009) The Etiologies of Ascites in the Internal Medicine Department at the University Hospital of Point G about 67 Cases. Thesis Medicine, Bamako, 1135.

[11] Gnonko, G.H.F. (2014) Interest of the Serum-Ascites Gradient in Albumin in the Diagnosis of Portal Hypertension. Thesis Medicine, Abidjan, 428.

[12] De Lisi, S. (2010) Oesophagogastroduodenoscopy in Patients with Cirrhosis: Extending the Range of Detection beyond Portal Hypertension. Digestive and Liver Disease, 10, 254-263.

[13] Mahassadi, K.-A., Ndri-Yoman, T., Attia, A., Doffou, S. and Bathaix, M.-F. (2008) Diagnostic Value of Ascitic Fluid Lymphocytosis and Serum-Ascites Albumin Gradient in Peritoneal Tuberculosis in the African Environment. Journal Africain d'Hépato-Gastroentérologie, 2, 152-157. https://doi.org/10.1007/s12157-008-0054-9

[14] Okon, A.J.B., Thot'o, A.S., N'dri, N., Soro, D., Diakité, M. and Ouattara, A. (2015) Interest Serum-Ascites Albumin Concentration Gradient in the Diagnosis of Esophageal Varices in Cirrhotic African, Abidjan (Côte d'Ivoire). Journal Africain d'Hépato-Gastroentérologie, 9, 85-89.

[15] Karki, D.B., Gurubacharya, D.L. and Mathura, K.C. (2005) Correlation between Serum-Ascites Albumin Concentration Gradient and Endoscopic Parameters of Portal Hypertension. Kathmandu University Medical Journal, 3, 327-333.

[16] Torres, E., Barros, P. and Calmet, F. (1998) Correlation between Serum-Ascites Albumin Concentration Gradient and Endoscopic Parameters of Portal Hypertension. The American Journal of Gastroenterology, 93, 2172-2178. https://doi.org/10.1111/j.1572-0241.1998.00615.x

[17] Akriviadis, E.A., Kapnias, D., Hadjigavriel, M., Mitsiou, A. and Goulis, J. (1996) Serum/Ascites Albumin Gradient: Its Value as a Rational Approach to the Differential Diagnosis of Ascites. Scandinavian Journal of Gastroenterology, 31, 814-817. https://doi.org/10.3109/00365529609010358

[18] Sampliner, R.E. and Iber, F.L. (1974) High Protein Ascites in Patients with Uncomplicaed Hepatic Cirrhosis. The American Journal of the Medical Sciences, 267, 275-279. https://doi.org/10.1097/00000441-197405000-00003

[19] Jiang, C.-F., Shi, B., Shi, J., Yuan, Z.-L. and Xie, W.-F. (2013) New Proposal for the Serum Ascites Albumin Gradient Cut-Off Value in Chinese Ascitic Patients. Diagnostic Pathology, 8, 143.

[20] Ahmad, N., Beg, M., Husain, S. and Akhtar, N. (2001) Serum-Ascites Albumin Gradient in Differential Diagnosis of Ascites. Journal, Indian Academy of Clinical Medicine, 2, 51-54. 